\title{
Toward a Parametric Model for Major Household Systems Performance
}

\section{Damian Rogers}

Ryerson University

\section{Filippo A. Salustri}

Ryerson University

\section{Norbert Hoeller}

Sustainable Innovation Network

digital.library.ryerson.ca/object/184

Please Cite:

Rogers, D., Salustri, F. A., \& Hoeller, N. (2009). Toward a parametric model for major household systems performance. Proceedings of the 5th International Conference on Environmental, Cultural, Economic and Social Sustainability, Mauritius.

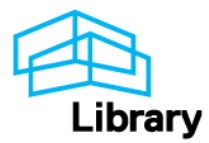




\title{
Toward a Parametric Model for Major Household Systems Performance ${ }^{1}$
}

\author{
D. Rogers, F.A. Salustri, N. Hoeller
}

\section{Introduction}

With the residential sector representing approximately $16.6 \%$ of total energy consumption in Canada (OEE, 2006) and 21\% in the United States (DOE, 2008), decisions that homeowners make on upgrades in their homes can have a large impact on national energy usage and greenhouse gas emissions. Since there remains a large amount of aging housing stock in Canada and worldwide, it is important to focus on educating the homeowners themselves in order to have a positive effect on home renovation projects. In fact, many studies have been conducted to survey and estimate the current state of national building stock in: Canada (Parekh, 2005), U.S.A. (Persily et al, 2006), Europe (Petersdorf et al, 2006), and Japan (Shimoda et al, 2003). These databases of building stock can help to identify major areas needing renovations in order to decrease residential total energy usage. Also, inclusion of these databases into the model would help to identify the best choice of defaults for a given user, based on information from the databases.

While updating local building codes helps to improve new houses being built, the only way to improve existing houses is through demolition or home renovation. It is here, in the renovation side of things, that the primary market for a tool of this kind would be used. Since home renovation projects are mainly chosen by the homeowners, it is important to educate the homeowners on the pros and cons of the various types of home upgrades available. Therefore, any tool of this kind would need to be simple and user-friendly in order to be used by a majority of homeowners and have an effect on residential energy usage.

Goals of this research are:

- To identify a need that is currently not being met by available modelling softwares

- Show that homeowners are key factors in home renovation decisions

- Provide easy to access and understandable information on how to improve housing performance

- Show by example that a tool of this kind works and is attractive to potential users

${ }^{1}$ Rogers, D., Salustri, F.A., Hoeller, N. (2009) Toward a Parametric Model for Major Household Systems Performance, Proceedings of the 5th International Conference on Environmental, Cultural, Economic and Social Sustainability 2009 
- Show that simplistic calculations, without full simulation/modelling, are effective and can yield worthwhile results

\section{Current Tools in the Market}

Tools that are currently used to model and estimate home energy usage can be classified into three categories for the purpose of comparison: easy to use, somewhat difficult to use, and hard to use. The following lists illustrate key characteristics of tools in these categories and also include some examples.

\section{Easy to use:}

- Examples: RETScreen, NEAT

- Most created by government agencies

- Tend to have simple, spreadsheet style interfaces

- Most are free to use

- Will not work without all inputs (little use of standard defaults)

- Background knowledge of the house is needed

- Little to no documentation or help for using these tools

\section{More difficult to use:}

- Examples: EnergyPlus, HOT2000/3000, EE4

- More extensive input and knowledge required

- Give better analysis than first category

- Some are still free to use

- User interfaces tend to be difficult to use

- Not recommended for non-experts

\section{Hard to use:}

- Examples: EsP-r, TRNSYS

- These use programming-like interfaces and inputs

- Not user friendly at all

- Can take days/weeks to configure and run a simulation

- Results can take hours/days to retrieve

- Offer a very detailed and accurate analysis

As can be seen by the above examples, there is currently nothing on the market which is attractive for homeowners/non-experts to use when deciding on home renovation projects. This unfilled niche limits the advantages that home renovation could deliver to national energy use in the residential sector. Therefore, it is recommended that a tool to fill this niche should be created, as it can increase the probability of a home update/renovation being done and that the renovation will be more energy efficient upon completion. 


\section{The Proposed Model}

It is envisioned that the tool will use a parametric model, easily updated to reflect changes in technologies, database information, etc. and will be aimed at users interested in modelling single family dwellings only. Aiming for a parametric model implies that the model should be as modular as possible. Also, modularity allows for the addition of sections in the future; making the model more robust and upgradeable. Thus, part of the design process for creating the tool was to design the modules that would be used and interconnected. The graphic below shows the final modular design of the model.

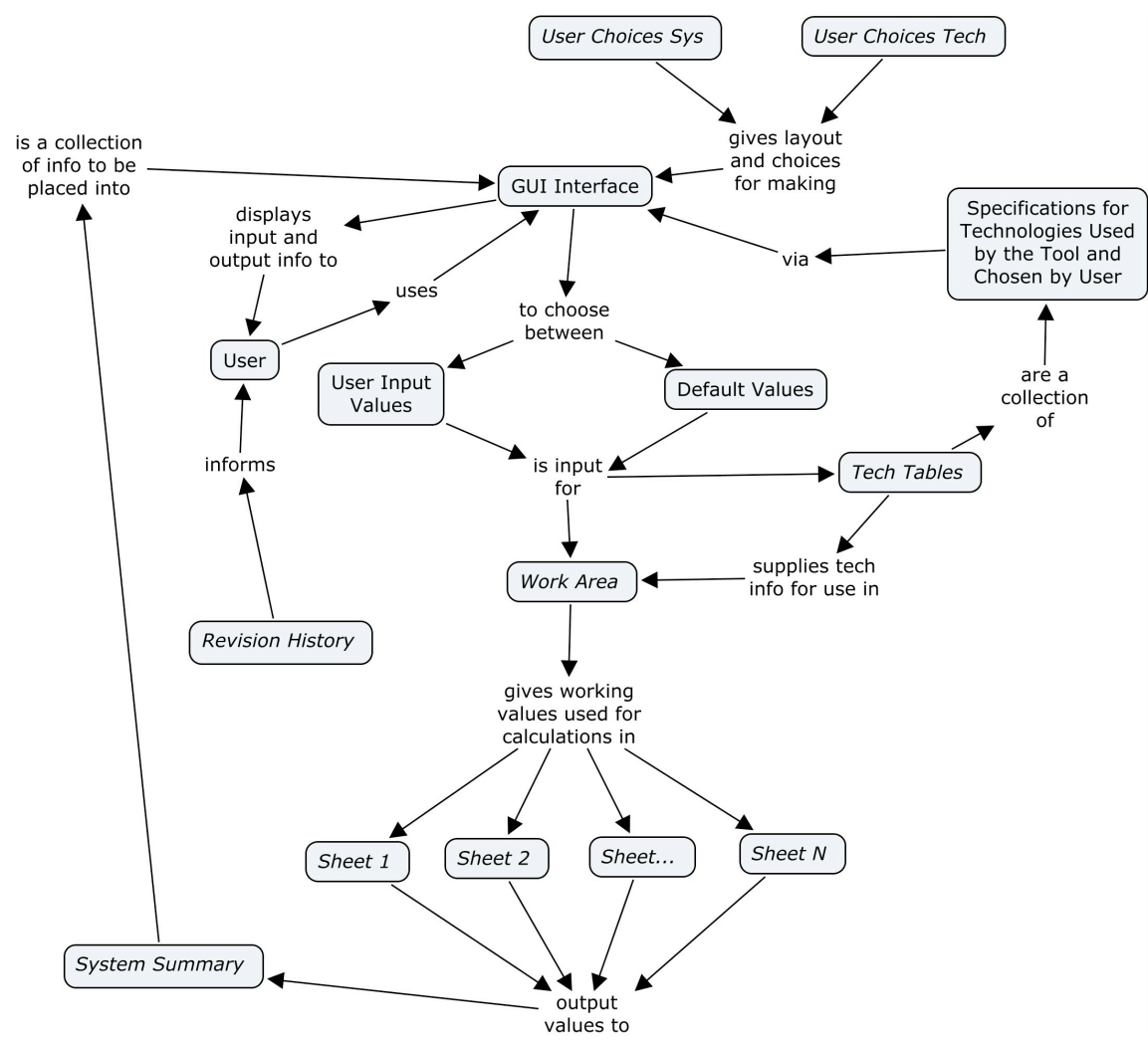

Figure 1: Modular Layout Design of the Parametric Modelling Tool

As can be seen by Figure 1 above, the user only interacts with the 'graphical user interface' (GUI), which allows a choice between default values embedded within the model or user-specified values. It should be noted that the GUI will have delimiters set up so that the user cannot input values outside the expected range. These choices are then given to the 'work area' module, which is used as an organizational as well as a testing module for the model during creation. It allows the tool designer flexibility in improving the tool without having to modify the GUI for every change in the tool. The rest of the modelling modules within the tool all receive their information from this 'work area', allowing simpler transfer of base information between the user and the rest of the tool. Each individual module within the tool would then perform the necessary calculations and output its values to another organizational and testing module, the 'system 
summary'. As is shown, the 'system summary' module then relays all information back to the GUI, which displays the information to the user in an easy-tounderstand fashion.

\section{Major Household Systems}

As indicated in the previous section, any tool created to serve the outlined need must be user-friendly and easy to use/understand. Therefore, for the sake of simplicity, the tool should only incorporate major household systems into the model. These 'major systems' would include: heating, ventilation, air conditioning, and refrigeration (HVAC\&R) ${ }^{2}$; domestic hot water (DHW) heating; lighting; and large appliances like fridges, stoves, and clothes dryers. Small appliances, resident occupancy, heat gains from lighting, and similar factors are left out of the modelling tool to increase simplicity. Time of use cases for these major systems are not taken into account in favour of using average annual usage figures. However, a simple percentage-based output of electrical savings, based on switching from one light bulb type to another, will be included in the tool as a way for homeowners to see the benefits of say compact fluorescent (CFL) bulbs over conventional incandescent or any other simple lighting change.

\section{Creating the Model}

Since the goal of this research is to provide a simple, easy to use tool for nonexperts, the interface should be one that is familiar to them. While there are many ways in which to display information in a simple way, people are most familiar with checkboxes, pull-down menus, and text boxes. Therefore, it would be beneficial to use input methods such as these.

Among different software packages that offer this type of display are: word processors, web pages, spreadsheets, and custom-made programs. Here, we exclude the use of a word processor as it has no ability to compute the mathematics of the model. This can also be said of web pages as they would have to communicate the input/output to some other form of software for computation. Custom-made programs offer the ability to create a very precise way of computing the output; however, the inability for a non-expert to go into the software to make a necessary change or to see how it works makes this choice a poor one. Therefore, a spreadsheet style was chosen for the creation of the parametric modelling tool. It offers the ability to create a simple, user friendly GUI, paired with computational abilities for computing the required outputs. The one aspect that suffers from choosing a spreadsheet over a custom made program is the accuracy of results. Given the input data and objectives stated, a tool with accuracy within $10 \%$, will still convey the desired information to the user: that an

\footnotetext{
2 Included in this system would be items such as: exterior cladding, insulation levels, windows, and basement type as these factors directly impact the HVAC\&R system.
} 
upgrade is either beneficial or not and that one upgrade might be better than another.

For reasons of keeping the computations simple enough for a spreadsheet to calculate and also in the interest of speedy delivery of results to the user, it was decided that first-order approximations for the calculations would suffice. That is to say that certain aspects and phenomena will be ignored, such as: computational fluid dynamics (CFD) models of air mixing, metabolic rates and occupancy loads of people within the home, time of day usage scenarios for systems, as well as others. Though ignoring these attributes leads to reduced accuracy, the model would still be able to output values which are accurate enough for the types of decisions that the users would make about potential renovations or upgrades to their home.

\section{Technology Tables}

One interesting feature of this model is the inclusion of the 'technology tables' as a module within the tool. In essence, the technology tables are a list of available technologies embedded in the tool, which can be modified to allow for the easy inclusion of any new technologies that might emerge from the time the tool is created. Thus, if a user wants to select a specific technology to see what the effects are on the output, they can easily do this with a simple drop-down menu from the GUI. The model then cross-references the choice with the identity of that item in the table and can take all of the parameters for that technology and bring them to the work area or to a specific module. An example of a proposed technology table entry for solar power generation can be seen in the Appendix ${ }^{3}$.

While the technology tables are a good way of keeping track of current technologies, it is envisioned that they could also serve as a way to test the performance of new technologies in this modelling tool. Including technologies which are currently not commercially available can show users what may be possible in the near future.

It is envisioned that future work will be able to include the EnerGuide Appliance Directory [OEE, 2007] directly into the technology tables such that the user can select each of their major home appliances for inclusion in the calculations. This will allow the user to then search for appliance upgrades when using the tool.

3 The 'technology tables' concept is originally a part of the Advanced Systems, Technologies, Research, and Analysis (ASTRA) Program at the National Aeronautics and Space Administration (NASA) [Mankins, 2004]. 


\section{Example of how the Tool Could be Used}

To illustrate the effectiveness of a tool of this sort, the following fictional example will help to provide insight as to the when, why, and how this tool might be used. For this example we will have two homeowners (User1 and User2), which live in identical houses in the same neighbourhood and know very little about energy efficiency upgrades and home renovations. They have both decided that their current utility bills are too high and wish to upgrade their houses to lower their bills and help the environment. The houses they live in are two-storey, older homes with single pane windows, R12 wall insulation, R30 attic insulation, and brick exterior cladding. Both use typical (for North America) forced air natural gas heating and central air-conditioning systems ${ }^{4}$.

The following sections will describe the decision making processes and possible outcomes for User1 and User2, where User1 will make an uninformed decision and User2 will use the proposed parametric modelling tool.

\section{User1 Scenario}

Not knowing much about home renovations and energy efficiency, User1 receives an advertisement in the mail outlining that high-efficiency furnaces are on sale from his utility provider and they will remove his old furnace for free. Knowing that his current furnace is $91 \%$ efficient and the new one boasts a $97 \%$ efficiency, he decided this must reflect a $6 \%$ increase in the total efficiency of his house and would most certainly lower his utility bills. Thus, he contacts the utility provider and receives his furnace upgrade only to be disappointed the following month to see that the changes in his utility bills are negligible. As a result of this unsuccessful attempt at energy efficiency, he then tells all the neighbours that 'the whole energy efficiency drive is just a ploy to get more money'; resulting in many neighbours choosing not to do any renovations to their own homes, which would neither be beneficial nor detrimental to the current state of affairs.

\section{User2 Scenario}

Also not knowing much about home renovations and energy efficiency and also receiving the same advertisement as User1, User2 decides to do some research to make his decision. A short search reveals a quick and easy-to-use parametric modelling tool, offering a simple comparison between home upgrades of major systems in the house, and which is also freely downloadable. User2 decides that 10 minutes of his time is well worth the information he will receive, so he begins to setup the tool. He sees a lot of choices in the GUI to help make the model more accurately depict his house, but since he does not know every detail

\footnotetext{
${ }^{4}$ It should be noted that the situations, scenarios, and outcomes in this example are entirely fictional and do not in any way represent actual events.
} 
about his home, he chooses to leave the tool-provided default values for some of the inputs.

Following User1's experience, he first tries changing his furnace type from the current $91 \%$ efficient model to the advertised $97 \%$ efficient model and sees that it results in a very minimal change in his overall energy usage (as he was told that User1 also experienced through his purchase). Next he focuses more on his house and remembers that he always feels uncomfortable drafts coming from his single pane windows, so he uses the tool to evaluate the potential of new, triple glazed, low-E, Argon-filled windows (which are installed professionally). Much to his surprise he sees the tool reports that this fairly simple upgrade can save him up to an estimated $6000 \mathrm{kWh}(\sim 20 \mathrm{M}$ BTU) over one year. Now, since he has no idea how much this is, he looks at his utility bills and sees this is about $15-20 \%$ of his total usage. This information allows him to easily estimate the payback on the upgrade. Having quickly found a beneficial upgrade, he has professionals install the new windows. A month later, while relaxing in the comfort of a house with fewer drafts, he reviews his utility bills and sees that he has saved near what the model predicted. Happy with this information, he boasts to his neighbours about his new windows and the tool that helped him. They in turn use it and do upgrades to their own homes, benefiting the environment.

\section{Conclusions}

In conclusion, the research has shown that the usefulness of a tool of this kind would be beneficial to homeowners and non-experts as a means of relaying information on home renovations and upgrades. It has also shown that with increased knowledge, there is a greater probability that users of this type of tool would make more informed decisions and that the decisions would benefit both themselves and the environment.

As is shown by the example included in this paper, a majority of home renovation decisions are made by the homeowner and/or occupant and these decisions are often influenced by advertisements, which may or may not accurately depict actual results. Thus, the research has successfully identified a niche area for a tool of this kind and a need which is currently not being met by tools on the market today. Given that there is a large amount of current building stock which is in need of retrofit and the potential of helping homeowners make informed renovation decisions, a modelling tool of the sort outlined in this paper would have a positive impact on energy demand in the residential sector.

Since this paper is more a feasibility study into whether or not a parametric model of this type would be useful, there is currently not a fully working prototype. However, there is a skeleton of a model which has been created using the layout design, as shown in Figure 1, and this is being used to demonstrate 
what the tool hopes to achieve. As part of this research, we intend to move on to create the computational modules for the tool.

Future work hopes to see the completion of a prototype tool for testing with actual users in the community. Also, the potential of including the EnerGuide Appliance Directory [OEE, 2007] in the tool as part of the technology tables will allow users to select their exact model of major appliances. This would make the tool more robust and appealing to potential users. 


\section{Appendix}

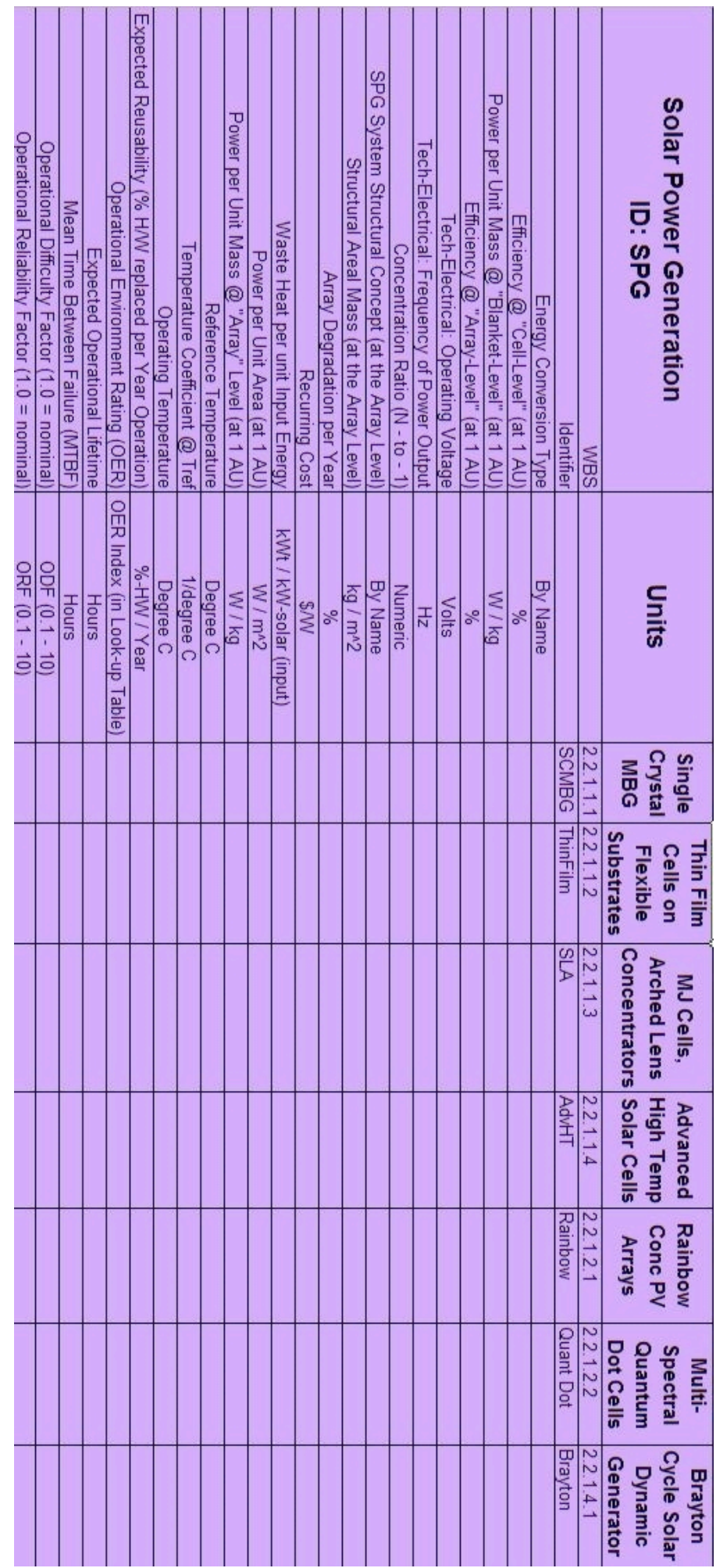




\section{References}

DOE. “Annual Energy Review 2007”. Energy Information Administration, US Department of Energy. 2008.

Mankins, J. "Advanced Systems, Technologies, Research, and Analysis to Enable Future Space Flight Capabilities and Realize the U.S. Vision for Space Exploration." National Aeronautics and Space Administration (NASA). Presented to the steering committee on February 23, 2004.

OEE. "Energy use data handbook- 1990 and 1998 to 2004". Office of Energy Efficiency, Natural Resources Canada. 2006.

OEE. "EnerGuide Appliance Directory 2007". Office of Energy Efficiency, Natural Resources Canada. 2007.

Parekh, A. "Development of archetypes of building characteristics libraries for simplified energy use evaluation of houses." Proceedings of the 9th International IBPSA Conference held in Montreal, 921-928. 2005.

Persily, A., Musser A., and Leber D. "A collection of homes to represent the U.S. housing stock." National Institute of Stand \& Technology Report No. NISTIR 7330 for US Department of Housing and Urban Development. 2006.

Petersdorf, C., Boermans T., and Harnisch J. "Mitigation of CO2 emissions from the EU15 building stock." Environ Sci Pollut Res (ESPR), 13[5], 350-358. 2006.

Shimoda, Y., Fujii T., Morikawa T., and Mizuno M. "Development of residential end-use simulation model at city scale." Proceedings of the 8th International IBPSA Conference held in Eindhoven, 1201-1208. 2003. 